\title{
A Case Study of Open Source and Public Participation in Catalyzing Social Innovations
}

\author{
Helen K. Liu \\ Dept. of Politics and Public Administration \\ The University of Hong Kong \\ Hong Kong \\ helenliu4@gmail.com
}

\author{
Jodi Sandfort \\ Humphrey Institute of Public Affairs \\ University of Minnesota \\ Minneapolis, MN, U.S.
}

\begin{abstract}
Our study investigates the use of a new open source platform in catalyzing social innovations and participation of its members over time. We empirically examined how the nature of project designs and social pressure affect contribution to the open source platform. In the twenty-one projects (3,998 contributions) from 2004 to 2009 , we find that the average number of contributions is higher when the projects are highly visible, when the project is designed to require specific skills from participants, and when it requires outcome measurement from participants' proposals. Also, we verified that actors join collective action when they believe their contribution is meaningful and they would stop when they believe their contribution could be marginal. These results provide implications for open source platform design in the philanthropic sector.
\end{abstract}

Keywords- Social Innovation; Open Source;Social Network Analysis

\section{INTRODUCTION}

In the recent years, an open source concept has become a widespread movement that successfully engages the public to participate in joint production, knowledge generation, and information sharing. Open source community has also become a new alternative communal connection for public engagement in generating social innovative solutions in the philanthropic sector. Previous studies have focused on the development and participation of open source community in the software industry and there is now a good deal of literature explaining this new phenomenon in the private sector. However, relatively little is known about this new concept in the philanthropic sector. In late 2004, Changemakers.org, a nonprofit organization, has initiated projects to connect individuals from around the globe to generate ideas or proposals for solving social issues [1]. It is important to further understand this new phenomenon and the linkages between this emerging open source community and its facilitation of public participation.

The purpose of this paper is therefore to investigate what new features of an open source community in the philanthropic sector are and to what extent those new features are related to public participation. We examine two streams of literature that provide some insight toward understanding how transparent and interactive characteristics of an open source community are associated with public participation. From a relational perspective, signaling incentives - including career concerns about referring to future job offers or future access to the venture capital market-create motivation for actors to participate in an open source community [2]. However, their study is based on the assumption that participants are self-interested while that might not be true to all. From a structural view, without emphasizing the self-interested assumption, actors would be willing to contribute to a collective action if they are sure that their contributions will not be wasted [3]. To investigate the extent to which those new features are related to public participation, we empirically test Lerner and Tirole's [2] and Gould's [3] theories and utilize an online archive database from Changemakers.org. We generate a panel data set that tracks participation from 3,627 actors to 21 open source projects from 2004 to 2009 . This data set provides project information and the history of actors' participation in the past five years for testing the four conditions proposed by Lerner and Tirole and Gould..

\section{LITERATURE AND HYPOTHESES}

\section{A. Relational Perspective}

Open source platform creates an environment for participants to demonstrate their ability. Participants generate reputation by demonstrating their ability in an open source community and this transparent community makes the reputations of the participant visible to the relevant audience [4]. Long-term incentive of maintaining a trustworthy relationship overcomes the short-term costs [2]. This proposition relies on a transparent environment for generating such long-term incentive. Actors' short-term contributions serve as a signal to their audiences, who could be their future employees [2]. Because of these features of open source community, long-term incentives are stronger when the open source community project design has the following three characteristics: (1) high visibility of the participants to the relevant audience, (2) clear information about the talents of the participants, and (3) participant impact on the outcome is measurable [2]. This suggests:

H1.1: The greater the visibility of a project to the relevant audience, the greater the contribution. 
H1.2: The more specific the skill requirement of a project, the greater the contribution.

H1.3: The better demonstration of the impact and effectiveness of participants' performance, the greater the contribution. Structure Explanations

\section{B. Structure Explanations}

A relational perspective provides one explanation of the relationship between the new features of open source community and participation of its members specifically. However, a relational theory [2] relies heavily on the selfinterest assumption that might not apply to all the participants in the philanthropic sector. Another stream of literature seeks an explanation from a structural perspective and emphasizes norms of the fairness. From a structural perspective, actors would only participate in a collective action if they see that the group is sufficiently large and will be successful in implementing the action [5] [3]. Selfinterest assumption under the relational theory is relaxed. Since open source community provides a transparent environment that allows actors to interact with each other. Therefore, the density and the quality of existing contributions within an open source community are important indicators for future participants. This suggests that:

H2.1: When the density and the number of contributions within a open source community increase, there will be more participation.

This hypothesis seems straightforward since actors often take for granted that project density and participation is linear. However, networks that are sparser may provide more chances for collaborative behavior [3]. Therefore, there is a threshold where the participant/contribution decreases as the density of a network increases [3] [6]. This suggests that:

H2.2: The relationship between the density, and participation is a non-linear one-i.e., the density and the number of contributions increase until a threshold is met and will decrease after the threshold.

\section{DATA AND METHOD}

To study the relationship between the new features of open source community in the philanthropic sector and participation of its members, we built a panel data set of the contributors to 21 Changemakers projects (from November 2004 to January 2009). Changemakers periodically announces new projects and each project stays posted for about three months. From 2004 until early 2009, it has attracted a total of 3,998 contributions and 11,014 discussions about the projects from approximately 150 countries. The range of the project categories includes humanitarian, civil society, environment, housing, health, youth, technology, and social entrepreneurship. We extracted the information about contributors and their entries that had been submitted to the Web site of Changemaker.org, using an extraction program. We identified distinct participants from those projects since some participants submitted multiple contributions to the same or different projects. Key information includes the name of contribution idea, the affiliated organization, country, number of discussions about a particular contribution, and date of submission. Table 1 summarizes the projects and highlights the fact that they differ considerably in size and other characteristics. We used the following variables in the study.

Table 1: Project Characteristics

\begin{tabular}{|c|c|c|c|c|c|c|c|}
\hline No. & Topic & Month & Year & Category & $\begin{array}{l}\text { \# of } \\
\text { Entries }\end{array}$ & $\begin{array}{c}\text { \#. of } \\
\text { Countries }\end{array}$ & $\begin{array}{l}\text { \# of } \\
\text { Disc. }\end{array}$ \\
\hline 1 & $\begin{array}{c}\text { How to Build a Citizen } \\
\text { Base that Supports an } \\
\text { Organization }\end{array}$ & Nov-Feb & 05 & Capacity & 105 & 39 & n.a. \\
\hline 2 & $\begin{array}{l}\text { How to End Human } \\
\text { Trafficking }\end{array}$ & Mar-Mar & 05 & Humanitarian & 69 & 21 & n.a. \\
\hline 3 & $\begin{array}{l}\text { How to Build a More } \\
\text { Ethical Society }\end{array}$ & Jun-Jun & 05 & Civil Society & 79 & 32 & n.a. \\
\hline 4 & $\begin{array}{l}\text { How to Create Market } \\
\text { Based Strategies that } \\
\text { Benefit Low Income } \\
\text { Communities }\end{array}$ & Aug-Aug & 05 & Housing & 128 & 38 & n.a. \\
\hline 5 & $\begin{array}{l}\text { Meeting Disaster: How } \\
\text { to Prepare }\end{array}$ & Oct-Oct & 05 & Humanitarian & 22 & 11 & n.a. \\
\hline 6 & $\begin{array}{l}\text { How to Improve Health } \\
\text { for All }\end{array}$ & Mar-May & 06 & Health & 139 & 40 & 492 \\
\hline 7 & $\begin{array}{c}\text { How to Provide } \\
\text { Affordable Housing }\end{array}$ & Jun-Sept & 06 & Housing & 86 & 28 & 272 \\
\hline 8 & $\begin{array}{c}\text { How to Entrepreneur } \\
\text { Peace }\end{array}$ & Oct-Jan & 07 & Civil Society & 158 & 41 & 226 \\
\hline 9 & That Was Easy & Nov-Feb & 07 & $\begin{array}{l}\text { Entrepreneur- } \\
\text { ship }\end{array}$ & 55 & 1 & 448 \\
\hline 10 & $\begin{array}{l}\text { No Private Matter! } \\
\text { Ending Abuse in } \\
\text { Intimate \& Family } \\
\text { Relations }\end{array}$ & Jan-May & 07 & Humanitarian & 31 & 13 & 176 \\
\hline 11 & $\begin{array}{l}\text { Ending Corruption: } \\
\text { Honesty Instituted }\end{array}$ & Feb-Jun & 2007 & Civil Society & 79 & 28 & 278 \\
\hline 12 & $\begin{array}{c}\text { Disruptive Innovations } \\
\text { in Health and Health } \\
\text { Care: Solutions People } \\
\text { Want }\end{array}$ & May-Aug & 07 & Health & 303 & 29 & 699 \\
\hline 13 & $\begin{array}{l}\text { Why Games Matter: A } \\
\text { Prescription for } \\
\text { Improving Health and } \\
\text { Health Care }\end{array}$ & Jul-Nov & 07 & $\begin{array}{l}\text { Technology/ } \\
\text { Health }\end{array}$ & 73 & 13 & 245 \\
\hline 14 & $\begin{array}{l}\text { Sport for a Better } \\
\text { World }\end{array}$ & Sept-Mar & 08 & Sport/Youth & 379 & 69 & 1818 \\
\hline 15 & $\begin{array}{l}\text { Young Men at Risk: } \\
\text { Transforming the } \\
\text { Power of a Generation }\end{array}$ & Nov-Mar & 08 & Youth & 357 & 38 & 1104 \\
\hline 16 & $\begin{array}{l}\text { Tapping Local } \\
\text { Innovation: Unclogging } \\
\text { the Water and } \\
\text { Sanitation Crisis }\end{array}$ & Jan-May & 08 & Environment & 263 & 54 & 736 \\
\hline 17 & $\begin{array}{l}\text { The Geotourism } \\
\text { Challenge: Celebrating } \\
\text { Places Changing Lives }\end{array}$ & Jan-Jun & 08 & Environment & 319 & 83 & 1723 \\
\hline 18 & $\begin{array}{c}\text { Ending Global Slavery: } \\
\text { Everyday Heroes } \\
\text { Leading the Way }\end{array}$ & Apr-Aug & 08 & Humanitarian & 236 & 48 & 1147 \\
\hline 19 & $\begin{array}{c}\text { Banking on Social } \\
\text { Change - Seeking } \\
\text { Financial Solutions for } \\
\text { All }\end{array}$ & Jul-Dec & 08 & $\begin{array}{l}\text { Social } \\
\text { Entrepreneur- } \\
\text { ship }\end{array}$ & 280 & 43 & 521 \\
\hline 20 & $\begin{array}{l}\text { Staples Youth Social } \\
\text { Entrepreneur } \\
\text { Competition }\end{array}$ & Aug-Nov & 08 & $\begin{array}{l}\text { Social } \\
\text { Entrepreneur- } \\
\text { ship }\end{array}$ & 514 & 60 & 665 \\
\hline \multirow[t]{2}{*}{21} & $\begin{array}{l}\text { The Power of Us: Re- } \\
\text { Imagine Media }\end{array}$ & Dec-Feb & 09 & Technology & 323 & 47 & 464 \\
\hline & Total & & & & 3998 & & 11014 \\
\hline
\end{tabular}




\section{Dependent Variable}

Project Participation. We consider individuals that participate in one or more Changemakers projects during the time period from November 2004 through January 2009 as one participant in the Changemakers communities. The total number of the Project Participation by January 2009 is 3,627 . But the number of participants varies throughout time.

\section{Independent Variable}

Project Content. We use two dummy variables to measure Project Content by using an indicator to show whether the content of the project requires [1] specific skills ${ }^{1}$ from the contributors to the project or [0] none. Another shows whether the project requires an outcome measurement: [0] none, [1] including effectiveness indicator, or [2] including specific impact measurement.

Project Visibility. We measure Project Visibility by using an indicator to show whether the project has a [1] high visibility or [0] low visibility. Visibility is measured by the total number of comments a project received. Any member of the Changemakers community can make comments on submitted projects. We assume that the number of comments a project received provides a proxy for how many times a project has been viewed and discussed. A project has a high visibility when the number of its comments is higher than the median number of the comments per project received.

Project Density. We measure project density $\Delta_{\bar{i}}$ as the number of contributions to project $i$ at a given time $t$, then divide that number by total potential contributions to project $i$ at the end of the project. To operate this variable, we divide the daily contribution by total contributions at the end of time $t$ for each project.

We then created a two mode relational time-series data set based on the information we extracted from the Changemakers archive. Two-mode data sets, also called affiliation networks, contain two parts. The first mode indicates actors, and the second mode in an affiliation network is a set of events. In our study, the first mode represents participants that make contributions to Changemakers projects and the second mode represents those projects to which the actors make contributions. For the 21 Changemakers projects, 3,627 participants that have submitted one or more contributions to those projects, and we tracked their contributions to various projects throughout the past four years. Those 3,627 organizations contributed a total 3,998 ideas to the Changemakers projects.

We first investigated and study the distribution of contributions to Changemakers projects by using project

\footnotetext{
${ }^{1}$ For coding this variable, we assess "competition framework" and "competition guidelines" report of each project (Project \#1 and Project \#17 do not have any reports). In those reports, we look for keys words-such as "talent," "skill," and "ability"- to see if those projects require specific skills. For instance, Project \#13, "Why Games Matter: A Prescription for Improving Health and Health Care," requires participants to have game developing and programming abilities. Project \#19, "Banking on Social Change," requires specific skills in financial services. Two doctoral students are involved in coding those 21 projects.
}

content and project density. We used a t test to discover if the differences of the contributions to the projects are significant under different project content categories or project density levels. Then, we imported our two-mode relational time-series data set into SoNIA, Social Network Image Animator [8], to animate how the network evolves through time.

\section{RESULTS AND CONCLUSIONS}

Our analysis seeks to understand the distribution of contributions to Changemakers projects by project density [3] and project characteristics [2]. Table 2 shows the distribution of average contributions to Changemakers projects by Project Visibility and Project Content as measured by Skill Requirement and Outcome Measurement (results available upon request). The first column shows that the average number of contributions to Changemakers projects with high visibility is more than three times the average contribution of projects with low visibility. In the second column, results show that the average contribution to Changemakers projects requiring a specific skill is about twice higher than the average contribution of projects without skill requirement. Finally, the average contribution to Changemakers projects that require the participants to specify impact indicators is nearly three times more than the average contribution to the projects that only require the participants to indicate effectiveness of the proposals. The average contribution to the projects with an impact indicators requirement is more than three times larger than the average contribution to the projects without any outcome measurements.

To understand how the distribution of participation in the Changemakers projects change throughout time, we then examine how actors' participation in a collective action changes according to the density of the group [3]. We find the number of projects started off low in the first month, reached a peak around the third month, and then gradually decreased until the project deadline for majority of those projects (results available upon request). It is similar to Gould's proposition [3] that actors are willing to participate when they feel that their contribution might be useful to the community regardless of winning the prize. But when the number of contributors reaches a point in which participants feel that their contribution is marginal, such as having similar ideas to the existing contributions, participants will not participate in the project. We find a correlation between project density and participation in Changemakers projects and verify Gould's theory [3].

To further investigate the evolution and development of the Changemakers community, we apply a virtualization tool from social network analysis and show how organizations exchange ideas for solving social issues through participating Changemakers projects. Figure 1 shows a series of sociograms that depict how the network of the Changemakers community changes through time. Visualization of the Changemakers community from a social network perspective helps identify two insights about the development of community that previous analyses cannot reveal: sub-groups and Bridgers. 
This community shows a fragmented network, there are separated subgroups that are not connected and not every actor can reach everyone. I Subgroups within a network indicate some uniqueness across those groups that are not connected. - The Geotourism Challenge: Celebrating Places Changing Lives - project requires participants to have very specific knowledge in both environmental policy and tourism. Some local hotels and local governments seem to have more interest in participating in this project in order to explore their local attractions. They are likely different from the rest of the organizations that participate in other Changemakers projects that focus on humanitarian, civil society, and social entrepreneurship improvement.

The rest of the projects are connected through Bridgers. Bridgers are defined as those who connect across different subgroups. We find 209 bridgers in the Changemakers community, accounting for $6 \%$ of the total organizations that participate in Changemakers projects. Those organizations have contributed ideas to at least two different projects in the past five years. We consider those organizations as active participants or idea brokers. Committed groups totaling $6 \%$ of a network community may seem small. But if we compare it to another online open source community, Wikipedia, which has only about $1 \%$ of regular and active members [9], Changemakers seems to attract a relatively large loyal group of members.

In summary, in the twenty-one projects with 3,998 contributions we tracked from 2004 to 2009, we find that the average number of contributions is higher when: (1) the projects attract a higher visibility, (2) the project is designed to require specific skills from participants, and (3) it requires outcome measurement from participants' proposals. We verify the theory of Lerner and Tirole [2] that participants contribute to the commons when the long-term incentives are greater. By contributing to the Changemakers community, those participants have opportunity to attract potential employees or granters. Also, we verify the Gould's theory [3] that actors join collective action when they believe their contribution is meaningful and they would stop when they believe their contribution could be marginal.

Our current analysis and data only allow us to confirm that there are correlations between project context designs and network contributions. We also confirm a relationship between project density and project contributions. However, we cannot make any claims on causality between the project contexts and project contribution or between project density and network contribution. Currently, we only have twentyone projects as our studied observations. Therefore, the result of this study could be highly case sensitive since the number of observations is small. But since Changemakers is the first organization that has adopted an open source concept and the only one in the philanthropic sector using it for generating socially innovative ideas, it still provides us with rare but valuable information for understanding the contributions to an open source community in the philanthropic sector.

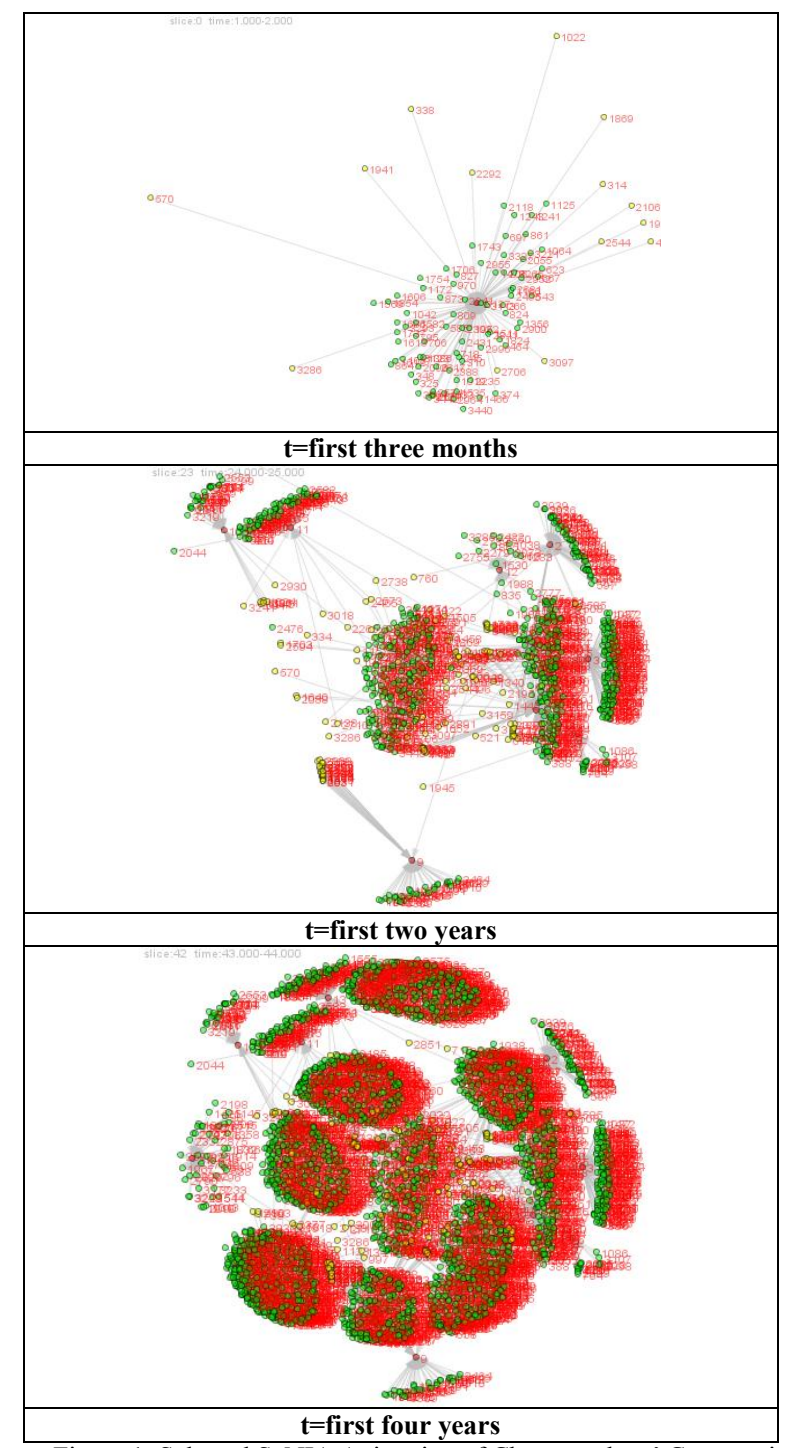

Figure 1: Selected SoNIA Animation of Changemakers' Community from Novermber 2004 to January 2009 with Twenty One Projects. Red Nodes Indicate Changemakers' Projects. Green Nodes Indicate Contributed Org. and Yellow Nodes Indicate Orgs. Have Contributed More Than Two Projects.

\section{REFERENCES}

[1] Berger, L. (2008). How Changemakers' "collaborative competitions" harness the wisdom of crowds.

[2] Lerner, J., \& Triole, J. (2002). Some Simple Economics of Open Source. Journal of Industrial Economics, 52, 197-234.

[3] Gould, R. V. (1993). Collective Action and Network Structure. American Sociological Review, 58, 182-196.

[4] Moon, J. Y. and L. Sproull. (2000). Essence of distributed work: the case of the Linux kernel. Firstmonday 5

[5] Fernandez, R. M., McAdam, D., 1988, Social networks and social movements: Multiorganizational fields and recruitment to Mississsippi freedom summer, Sociological Forum 3, 441-460.

[6] Chwe, Michael Suk-Young. 1999. "Structure and Strategy in Collective Action," Amer. J. Sociology 105, pp. 128-56.

[7] Bender-deMoll, Skye, and Daniel A. McFarland. 2002. SoNIA (Social Network Image Animator). See http://sonia.stanford.edu/

[8] Wales, Jimmy, (2005). "The Intelligence of Wikipedia" webcast, Oxford Internet Institut 